\title{
Study on the Equivalent Fire Load of Axially Loaded Concrete Columns
}

\author{
Lin $\mathrm{Li}^{1, \mathrm{a}}$ and $\mathrm{Hui} \mathrm{Li}^{2, \mathrm{~b}}$ \\ ${ }^{1}$ Fujian Jiangxia University, Fuzhou, Fujian, P. R. China \\ ${ }^{2}$ Huazhong University of Science and Technology, Wuhan, Hubei, P.R. China

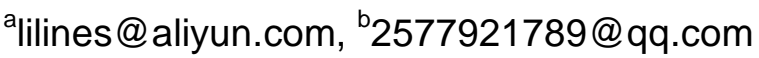

Keywords: Equivalent fire load, Concrete column, Temperature contour

Abstract. Building fire is dangerous to structures. It is important to accurately compute the equivalent fire load. First, temperature fields of a reinforced concrete column with four face exposed to fire were simulated using finite element method. Then, two step simplified model was applied to compute the transformed area of the column. Finally, the equivalent fire load was obtained based on the transformed area. Result shows that the method is applicable to compute the equivalent fire load.

\section{Introduction}

Building fire is a kind of common disaster. Building fire causes structural members high temperature, which will make the strength of concrete decrease. More and more researchers pay attention to anti-fire performance of reinforced concrete members or structures [1-3]. When the loads applied to the members remain unchanged, the stresses of the members increase with temperature rising. Suppose that the effective bearing sections of the structural members remain unchanged, it is equivalent to apply an increasing load with time. Therefore, effect of building fire can be equal to an extra load applied to structural members.

Columns are very important members in structures. When the bearing capacities of the columns are insufficient with occurrence of building fire, the structures may collapse. Therefore, it is important to study the equivalent fire load of columns suffering building fire. Axially loaded concrete columns are typical compressive members. In this study, the axially loaded concrete columns are acted as research objective, which is the basis of further study.

\section{The Equivalent Sections of Concrete Columns suffering building fire}

It can be assumed that concrete loses its strength when the temperature of the concrete is above a specific value, as the compressive strength of concrete decreases with temperature rising. Lin and Liu assume that the strength of concrete does not decrease when the temperature of concrete is below 500 ${ }^{\circ} \mathrm{C}$ and loses bearing capacity completely when the temperature is above $500^{\circ} \mathrm{C}$ [4]. The assumption is simple but not accurate, which ignore the residual strength of concrete with temperature above $500^{\circ} \mathrm{C}$ . In this study, we assume that the strength of concrete does not decrease when the temperature of concrete is below $300^{\circ} \mathrm{C}$, the strength decreases by $50 \%$ when the temperature is between $300^{\circ} \mathrm{C}$ and $800^{\circ} \mathrm{C}$, and loses bearing capacity completely when the temperature is above $800^{\circ} \mathrm{C}$, as shown in Fig. 1. It will be more accurate to estimate the equivalent section of concrete columns. Therefore, the area of the equivalent section of a concrete column is the sum of the area with temperature below $300^{\circ} \mathrm{C}$ and half the area with temperature between $300^{\circ} \mathrm{C}$ and $800^{\circ} \mathrm{C}$.

For a rectangle concrete column with the dimensions $b \times h$, its four faces are exposed to fire. The temperature contours of $300^{\circ} \mathrm{C}$ and $800^{\circ} \mathrm{C}$ are shown in Fig. 2. They can be treated as rectangles approximately with dimensions $b_{3} \times h_{3}$ and $b_{8} \times h_{8}$ respectively. The equivalent width, height and area of the rectangular concrete column are as follows, 


$$
\begin{aligned}
& b_{\mathrm{T}}=b_{3}+\frac{1}{2}\left(b_{8}-b_{3}\right)=\frac{1}{2}\left(b_{8}+b_{3}\right), \\
& h_{\mathrm{T}}=h_{3}+\frac{1}{2}\left(h_{8}-h_{3}\right)=\frac{1}{2}\left(h_{8}+h_{3}\right), \\
& A_{\mathrm{T}}=b_{T} h_{T}=\frac{1}{4}\left(b_{8}+b_{3}\right) \cdot\left(h_{8}+h_{3}\right) .
\end{aligned}
$$

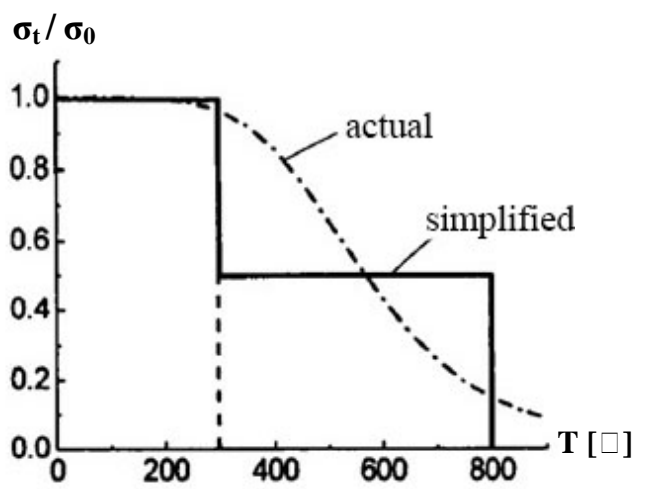

Fig. 1 Model of strength of concrete
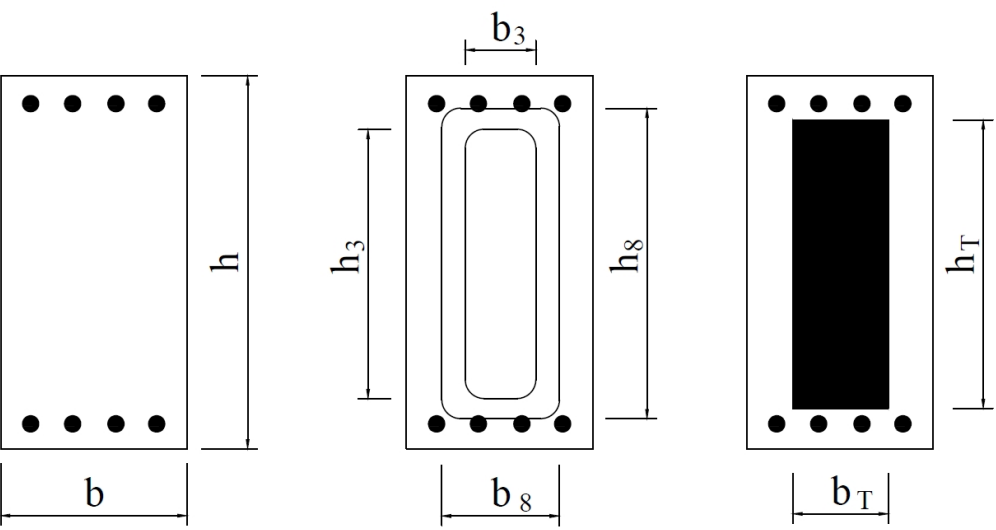

Fig. 2 Rectangular column with four faces exposed to fire

\section{The Transformed Areas of Reinforced Concrete Columns}

Because of the difference in elastic modulus between rebar and concrete, the area of rebar can be transformed into that of concrete. The initial transformed area of reinforced concrete column $A_{0}$ is,

$$
A_{0}=b h+(n-1) A_{\mathrm{s}},
$$

where $n$ is the ratio of the elastic modulus of rebar to that of concrete, and $A_{s}$ is the area of rebar. The transformed area of reinforced column at time $t$ is,

$$
\begin{aligned}
& A_{t}=A_{\mathrm{T}}+(n-1) A_{\mathrm{s}}, \quad a_{t} \leq c, \\
& A_{t}=A_{\mathrm{T}}+(n-1)\left(A_{\mathrm{s}}-A_{\mathrm{s}}{ }^{\prime}\right), \quad a_{t}>c,
\end{aligned}
$$


Where $A_{\mathrm{s}}$ and $A_{\mathrm{s}}{ }^{\prime}$ are the area of all rebar and that of the rebar lost bearing capacity respectively, and $a_{t}$ is the thickness of concrete lost bearing capacity. $a_{t}$ can be expressed as follows,

$$
a_{t}=\frac{1}{2} b-\frac{1}{4}\left(b_{3}+b_{8}\right) \quad \text { or } \quad a_{t}=\frac{1}{2} h-\frac{1}{4}\left(h_{3}+h_{8}\right) \text {. }
$$

\section{The Equivalent Fire Load of Axially Loaded Reinforced Concrete Columns}

The stress of a rectangular column with four faces exposed to fire at time $t, \sigma_{t}$, is,

$$
\sigma_{t}=N_{0} / A_{t}
$$

Where $N_{0}$ is the axial force. Suppose that the stress of $A_{0}$ is $\sigma_{t}$, and then we can obtain a greater axial force, $N_{t}$. $N_{t}$ has the following expression,

$$
N_{t}=\sigma_{t} \cdot A_{0}
$$

The difference is the equivalent fire load, $F_{\mathrm{e}} . F_{\mathrm{e}}$ can be expressed as follows,

$$
F_{\mathrm{e}}=N_{t}-N_{0}
$$

Substituting Eq. (8) and (9) into Eq. (10) yields

$$
\frac{F_{\mathrm{e}}}{N_{0}}=\frac{A_{0}}{A_{t}}-1
$$

Where $F_{\mathrm{e}} / N_{0}$ is relative equivalent fire load.

\section{Numerical Example}

In this study, the example of Lie and Irwin [5] is used to compute the equivalent fire load. First, temperature fields at different time are simulated by finite element analysis. And then, the temperature contours of $300 \square$ and $800 \square$ are obtained based on the temperature fields. The distance between temperature contours and the surface of column is shown in Table 1. Finally, the relation between the relative equivalent fire load and fire duration is derived, as shown in Fig. 3.

It is can be found that the relative equivalent fire load gradually increases with time. When the rebar lose its bearing capacity, the relative equivalent fire load increases more quickly. When fire duration lasts 3 hours, the equivalent fire load is approximately triple the axial force.

Table 1 The distance between temperature contours and the surface of column [mm]

\begin{tabular}{lcccccc}
\hline Time $[\mathrm{min}]$ & 30 & 60 & 90 & 120 & 150 & 180 \\
\hline $\mathrm{C}_{1}=300 \square$ & 30.5 & 45.75 & 76.25 & 91.5 & 104.17 & 119.42 \\
$\mathrm{C}_{2}=800 \square$ & 0 & 15.25 & 29.21 & 35 & 45.75 & 58.42 \\
\hline
\end{tabular}




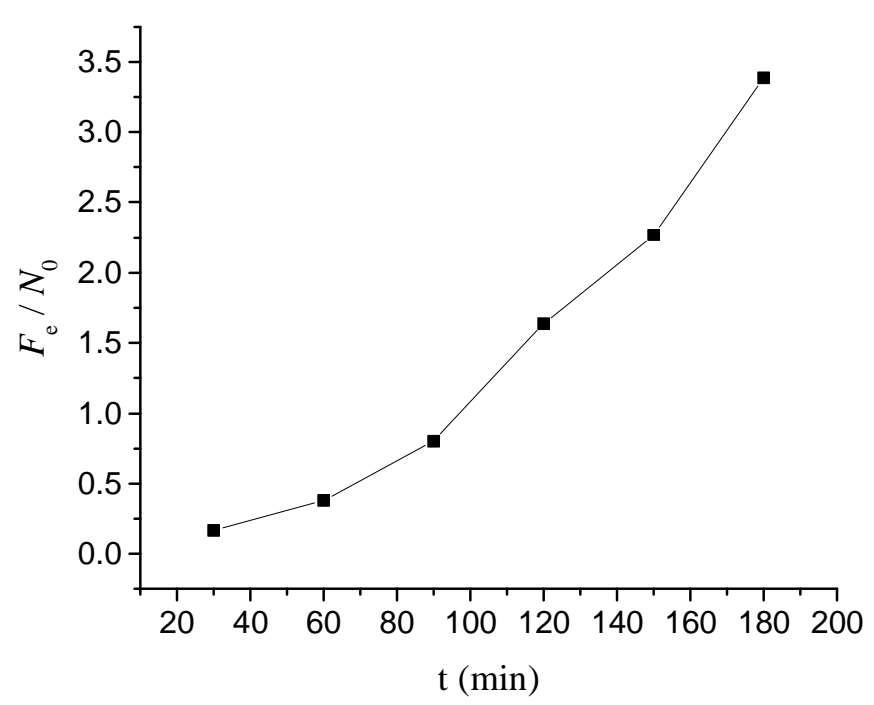

Fig. 3 The relation between the relative equivalent fire load and fire duration

\section{Conclusions}

By using ANSYS thermal analysis, we can obtain the temperature distribution in cross section at different time. According to demand, temperature contours at different time can be extracted. Instead of $500{ }^{\circ} \mathrm{C}$ boundary, two step simplified model was used to compute the equivalent fire load. Result shows that the method is applicable for reinforced concrete columns with four faces exposed to fire.

\section{Acknowledgements}

This work was financially supported by the National Natural Science Foundation of China (Grant No. 51278214).

\section{References}

[1] T.T. Lie and B. Celikkol. Method to calculate the fire resistance of circular reinforced concrete columns. ACI Material Journal, 1991, 88(1): 84-91

[2] J. P. C. Rodrigues, L. Laim and A. M. Correia. Behaviour of fiber reinforced concrete columns in fire. Composite Structures. 2010, 92(5): 1263-1268.

[3] C.G. Bailey and E. Ellobody. Fire tests on bonded post-tensioned concrete slabs. Engineering Structures. 2009, 31(3): 686-696.

[4] D. Liu and M. Lin. Calculation of equivalent fire load for RC members subjected to fire. Journal of Harbin Engineering University. 2007, 28(5): 519-524. (In Chinese)

[5] T.T. Lie and R.J. Irwin. Fire resistance of rectangular steel columns filled with bar reinforced concrete. Journal of Structural Engineering, 1995, 121(5): 797 805. 